\title{
EPIDEMIOLOGY OF HUMAN CRYPTOSPORIDIOSIS IN IRELAND, 2004-2006: ANALYSIS OF NATIONAL NOTIFICATION DATA
}

\author{
Patricia Garvey (patricia.garvey@hse.ie) ${ }^{1}$, P McKeown ${ }^{1}$ \\ 1. Health Protection Surveillance Centre, Dublin, Irelandl
}

\begin{abstract}
Cryptosporidium is a protozoal parasite which is of public health interest primarily due to its frequent association with drinking water. Since cryptosporidiosis became a notifiable human disease in 2004 in Ireland, evidence has been growing as to the national burden of illness caused by this pathogen. Nationally, crude incidence rates of between 8.7 and 13.4 per 100,000 were reported annually in the period 2004-2006. Rural areas reported more cases, with regional incidence rates as high as $31.4 / 100,000$ per year. Over this time period, there has consistently been a peak in the number of notifications in springtime, contrasting with the reported seasonal distribution of cases elsewhere in Europe. Outbreak surveillance data suggest that drinking water is an important transmission route for general outbreaks, with person-to-person spread more common in family outbreaks. Cryptosporidium is an important gastrointestinal pathogen in Ireland, with much still to be learned about its epidemiology here.
\end{abstract}

\section{Introduction}

Cryptosporidium is a protozoal parasite which first came to prominence as a cause of chronic diarrhoea in acquired immunodeficiency syndrome (AIDS) patients in the United States in the early eighties, but is now recognised as a major cause of gastroenteritis in immunocompetent patients, leading to a spectrum of disease from asymptomatic shedding to watery non-bloody diarrhoea, sometimes accompanied by abdominal pain, nausea, anorexia, fever and weight loss.

A key feature of Cryptosporidium oocysts is their relative resistance to chlorination, and as a result, it has gained notoriety as a public health issue due to its association with municipal drinking water supplies and public swimming pools, both of which have been implicated as the vehicle of transmission in a number of outbreaks in developed countries [1-4].

Awareness of cryptosporidiosis as a cause of gastrointestinal illness has risen in Ireland in 2007 due in part to a large waterborne outbreak in a city in the west of Ireland [5], which resulted in an extended boil water notice for several months. Evidence as to the national burden of illness caused by this pathogen, however, has been growing since 2004, when cryptosporidiosis became a notifiable human disease. This paper outlines current knowledge of the national epidemiology of human cryptosporidiosis in Ireland, drawing on recent disease notification and outbreak surveillance data.

\section{Materials and methods}

Human cryptosporidiosis has been subject to mandatory notification in Ireland since 1 January 2004. As for all notifiable diseases, basic demographic data is reported routinely on all cases. The case definition adopted since 2004 is based on the European Union (EU) case definition [6]. Notification data are maintained in the Computerised Infectious Disease Reporting (CIDR) system, a central national repository for all infectious disease notification data in Ireland. The notification data used in this report is based on information retrieved from CIDR on cases of cryptosporidiosis reported from 2004 to 2006, as of 5 December 2007.

Reporting of infectious disease outbreaks has been mandatory in Ireland since 1 January 2004, and data on outbreaks of cryptosporidiosis between 2004 and 2006 were retrieved from CIDR for that time period. Prior to 2004 , outbreak data had been collected on a non-statutory basis from July 2001 by the Health Protection Surveillance Center (HPSC). In this paper, we present data collected on outbreaks reported between July 2001 and December 2006.

The administration of public health activities in Ireland is divided into eight regional departments, referred to as Health Service Executive (HSE) areas. Regional incidence rates were calculated as crude incidence rates per 100,000 population using Central Statistics Office (CSO) population data from the 2006 census as denominator. For age-specific incidence rates, seven cases were omitted from the analyses, as the variable 'age' was not available.

\section{Results and discussion}

\section{Incidence}

In the three years from 2004 to 2006, between 367 and 568 cases of cryptosporidiosis were notified annually, resulting in a crude incidence rate (CIR) of between 8.7 and 13.4 per 100,000 population (Table 1).

To put this in perspective relative to other causes of intestinal infectious disease in Ireland, the reported incidence of cryptosporidiosis is similar to that of salmonellosis in the same time period. A recent study [7] compared the incidence of cryptosporidiosis in 16 countries in Europe in 2005, and reported an overall crude incidence rate of 1.9 per 100,000 in these countries, with Ireland having the highest CIR of the 16 countries included in the study. Even bearing in mind that comparison between surveillance data from different countries is difficult due to variation in diagnostic, investigative, and surveillance practices, 
all of which influence reporting in each of the countries, it is clear that cryptosporidiosis is an important cause of gastrointestinal illness in Ireland.

\section{Seasonal distribution}

Between 2004 and 2006 in Ireland, there was a consistent pattern in the seasonal distribution of notifications (Figure 1), with the highest numbers of cases reported from April to June. Overall, $55 \%$ of cases occurred during the second quarter of the year in these three years.

This contrasts strongly with the seasonal distribution of cases reported in the United Kingdom (UK), Sweden and Germany [7], where the highest numbers of cases in 2005 occurred in autumn, and with Spain, where a seasonal peak was observed in June, suggesting that the epidemiology of cryptosporidiosis in Ireland differs appreciably from the current epidemiology of cryptosporidiosis in these countries. Spring peaks in incidence coincide with peak calving and lambing activities, and are believed to be associated primarily with transmission from animal sources [8-9]. Prior to the introduction of the 1999 UK water regulations, there had been both a spring and an autumn peak in the number of cases, whereas in the recent years a significant reduction in the number of spring cases has been noted and attributed to the effectiveness of these regulations [10].

It appears that the seasonal distribution of cases in Ireland more closely reflects that reported for New Zealand, which also displays a pronounced spring peak, albeit in addition to a smaller autumn peak [11]

\section{Age-sex distribution}

Figure 2 shows the mean annual age-specific incidence rate in Ireland 2004-2006. Notifications for children predominated with over three quarters of all reported cases being less than 10 years of age. There were more male $(n=729)$ than female $(n=634)$ cases notified.

It is widely accepted that there is a degree of bias in reporting of illness in young children for many diseases, as parents are more likely to seek medical attention and health personnel more likely to take specimens for children than for adults. Moreover, higher incidences among younger children may reflect a lack of immunity as many older people may have already had exposure to Cryptosporidium during their lifetime.

However, selective criteria based on age are also commonly applied to samples for Cryptosporidium testing in diagnostic laboratories (a selection criterion probably not as frequently applied when testing for other common gastrointestinal pathogens such as Salmonella or Campylobacter), and this could have a significant impact on the reported age distribution. For example, although the HPSC report on waterborne cryptosporidiosis [12] recommends that all stool specimens received by laboratories from symptomatic individuals be tested for Cryptosporidium, it acknowledges that where resources are limited an age threshold of ten years can be applied, although this threshold is generally not employed during outbreaks. The effect on the reported incidence of disease in Ireland will be dependent on the number of laboratories that have opted to apply an age threshold as a selective criterion when examining specimens for Cryptosporidium. Anecdotally, we are aware that many laboratories do not test routinely for Cryptosporidium in adults, and a laboratory survey to investigate this further is underway. The recent outbreak in the west of Ireland provides some evidence of the potential effect of an age threshold selective criterion [5]. It was reported that more than $40 \%$ of cases in the outbreak were older than 15 years of age. On this basis, it is possible that in areas served by diagnostic laboratories where an age-threshold such as this is applied, around $40 \%$ of cases could remain undetected.

\section{Regional distribution}

There was a marked difference between the reported incidence of cryptosporidiosis in the HSE-East (which includes the capital city Dublin and thus has a larger proportion of urban dwellers that other HSE areas) and other more rural areas of Ireland (Table 1). The highest average crude incidence rate in 2004-2006 was reported in the HSE-West $(22.5 / 100,000)$, which had a particularly high incidence in 2005 (31.4/100,000), followed by HSE-Midlands (18.2/100,000), where data were influenced by the occurrence of a community outbreak in 2004 , which resulted in a higher than average incidence in that year.

T A B L E 1

Crude incidence rates (CIR) of cryptosporidiosis by Health Service Executive (HSE) area and year, Ireland, 2004-2006

\begin{tabular}{|l|c|c|c|}
\hline \multirow{2}{*}{ HSE area } & \multicolumn{3}{|c|}{ CIR (95\% confidence interval) } \\
\cline { 2 - 4 } & 2004 & 2005 & 2006 \\
\hline East & $1.5(0.9-2.2)$ & $2.5(1.7-3.3)$ & $0.5(0.1-0.8)$ \\
\hline Midland & $24.6(18.5-30.8)$ & $14.3(9.6-19.0)$ & $15.5(10.6-20.4)$ \\
\hline North-East & $12.5(8.8-16.1)$ & $15.5(11.5-19.6)$ & $1.5(0.9-2.1)$ \\
\hline North-West & $7.6(4.9-10.3)$ & $15.7(11.8-19.7)$ & $15.5(11.5-19.6)$ \\
\hline South-East & $16.9(11.6-22.1)$ & $18.1(12.7-23.6)$ & $7.1(4.5-9.7)$ \\
\hline South & $17.4(13.6-21.2)$ & $21.3(17.1-25.5)$ & $12.7(8.1-17.2)$ \\
\hline West & $11.9(9.2-14.6)$ & $16.9(13.7-20.1)$ & $13.2(9.9-16.6)$ \\
\hline Ireland & $18.6(14.4-22.7)$ & $31.4(26.0-36.8)$ & $11.9(9.2-14.6)$ \\
\hline
\end{tabular}

Data source: Computerised Infectious Disease Reporting (CIDR), Health Protection Surveillance Centre (HPSC), Ireland 
Contact with farm animals and visiting farms are known risk factors for sporadic cryptosporidiosis. Living in an area with poorer water treatment has also been reported as a risk factor for cryptosporidiosis. Moreover, a high proportion of rural dwellers in Ireland are served by private wells, many of which would not have barriers against Cryptosporidium. We believe that the lower incidence reported from the HSE-East may reflect at least in part a true difference in risk between urban and rural dwellers.

There was also a noticeable difference between the age distribution of cases in different HSE areas. For example, the HSE-East reported a higher proportion of adult cases older than 15 years of age among their relatively small number of cases almost three quarters of cases reported in the period 2004-2006 (Table 2). Interestingly, several of these cases were reported as travel-associated. In contrast, only $5-8 \%$ of cases in the HSE-West and HSE-Mid West during the same period were above the age of 15 years. Some of this variation is likely to be due to surveillance bias as discussed above.

F I G U R E 1

Seasonal distribution of cryptosporidiosis cases, Ireland, 2004-2006

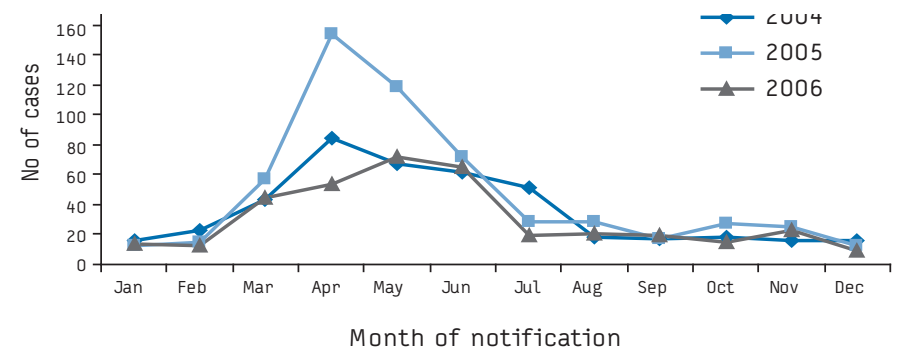

Data source: Computerised Infectious Disease Reporting (CIDR), Health Protection Surveillance Centre (HPSC), Ireland

F I G U R E 2

Mean annual age-specific incidence rates of

cryptosporidiosis, Ireland, 2004-2006

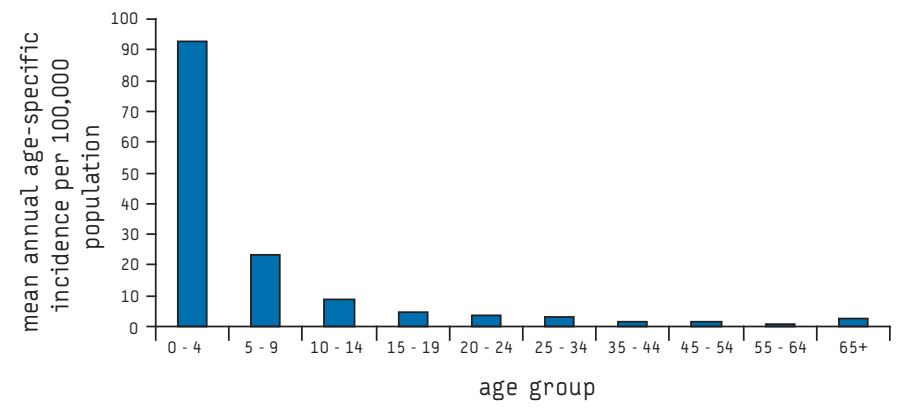

Data source: Computerised Infectious Disease Reporting (CIDR), Health Protection Surveillance Centre (HPSC), Ireland

\section{Transmission routes for cryptosporidiosis in Ireland}

Outbreak surveillance data provide important information on disease transmission routes. Between July 2001 and December 2006, 23 outbreaks of cryptosporidiosis were reported to the HPSC, including nine family outbreaks and 14 general outbreaks (outbreaks involving cases who were not part of the same family) (Figure 3). Water was reported as a suspected source for 14 outbreaks - drinking water for twelve outbreaks ( 11 general and one family outbreak) and recreational water for two family outbreaks. For general outbreaks, drinking water was the most common suspected transmission route, while for family outbreaks personto-person transmission appears more important (Figure 3). For one waterborne outbreak during this time period, there was analytical evidence demonstrating a statistically significant increase in the likelihood of disease in those who consumed tap water [13].

Some of the best available evidence internationally on the epidemiology of Cryptosporidium is from the United Kingdom [3,8,14-19]. Evidence has been gathered through a combination of outbreak surveillance, case control studies and speciation of positive human specimens from routine human surveillance. The most commonly reported outbreak transmission routes in England and Wales have been public water supplies and swimming pools $[3,14,19]$. Swimming pools have not been reported as a location for outbreaks for cryptosporidiosis in Ireland during this time period, although there were cases reported associated with an outbreak linked to a swimming pool in Spain in 2003 [20].

Since surveillance for human cryptosporidiosis began in 2004 following the revision of the list of notifiable diseases [21], much has been learned about the epidemiology of human cryptosporidiosis in Ireland. There remain, however, a number of issues on which further data would be advantageous. In the United Kingdom, speciation of human isolates has proved invaluable in elucidating the epidemiology of infection in conjunction with case control studies and other surveillance data [19]. In the time period 2004-2006 in Ireland, typing of positive human specimens was only rarely undertaken except in the event of outbreaks. A small number of hospital laboratories in Ireland have started to have Cryptosporidium-positive specimens typed on a routine basis

T A B L E

Age distribution of cryptosporidiosis notifications, Ireland, 2004-2006, by Health Service Executive (HSE) area

\begin{tabular}{|l|c|c|c|c|}
\hline HSE- area & $<\mathbf{5}$ yrs & $\mathbf{5 - 1 4}$ yrs & $\mathbf{1 5 +}$ yrs & Total \\
\hline East & $13(19.4 \%)$ & $5(7.5 \%)$ & $49(73.1 \%)$ & 67 \\
\hline Midland & $99(72.3 \%)$ & $25(18.2 \%)$ & $13(9.5 \%)$ & 137 \\
\hline Mid-West & $103(66.0 \%)$ & $41(26.3 \%)$ & $12(7.7 \%)$ & 156 \\
\hline North-East & $68(56.7 \%)$ & $24(20.0 \%)$ & $28(23.3 \%)$ & 120 \\
\hline North-West & $62(55.9 \%)$ & $33(29.7 \%)$ & $16(14.4 \%)$ & 111 \\
\hline South-East & $134(56.1 \%)$ & $34(14.2 \%)$ & $71(29.7 \%)$ & 239 \\
\hline South & $152(60.1 \%)$ & $59(23.3 \%)$ & $42(16.6 \%)$ & 253 \\
\hline West & $208(75.4 \%)$ & $53(19.2 \%)$ & $15(5.4 \%)$ & 276 \\
\hline Total & $839(61.7 \%)$ & $274(20.2 \%)$ & $246(18.1 \%)$ & 1359 \\
\hline
\end{tabular}

Note: includes only cases where information on age was available

Note: includes only cases where information on age was available Data source: Computerised Infectious Disease Rep 
since 2007, and the results of these studies will provide the first systematic evidence of the relative importance of different species in this country. Provisional results from these studies suggest that C. parvum is more common than $\mathrm{C}$. hominis among sporadic cases in Ireland (unpublished data). A research study by Zintl et al [22] concurs with this.

Another issue that needs to be assessed quantitatively is the relative importance of travel-associated infection. In the United Kingdom, international travel is believed to play an important part in the epidemiology of Cryptosporidium in autumn months. The available data at national level in Ireland on 'country of infection' is limited but has been improving over time. Given that a number of community outbreaks have been reported in Ireland, it is likely that indigenous cases form the majority of cases, however, this would be important to verify, and hopefully can be achieved with time.

Increasingly, circumstantial evidence from outbreak surveillance data in Ireland suggests that drinking water and person-to-person spread are important transmission routes during outbreaks. Elsewhere, personal risk factors for sporadic cryptosporidiosis have variously included factors such as international travel, contact with cattle, visiting farms, contact with another person with diarrhoea, swimming in a public swimming pool, freshwater swimming, having a chronic medical condition, and drinking unboiled tap water [1516, 23-26]. Socio-economic risk factors such as living in an area which has a high proportion of individuals of higher socio-economic status, living in an area with a high rate of manure application to land, or living in an area with poorer water treatment, were reported by Lake et al [27]. A key advantage of the Hunter study was that analyses of the case control study were undertaken separately for $C$. parvum and $C$. hominis cases permitting determination of the species-specific risk factors [15]. The only factor which significantly

\section{F I G U R E 3}

Outbreaks of cryptosporidiosis in Ireland, July 2001 December 2006, by suspected transmission route $(n=23)$

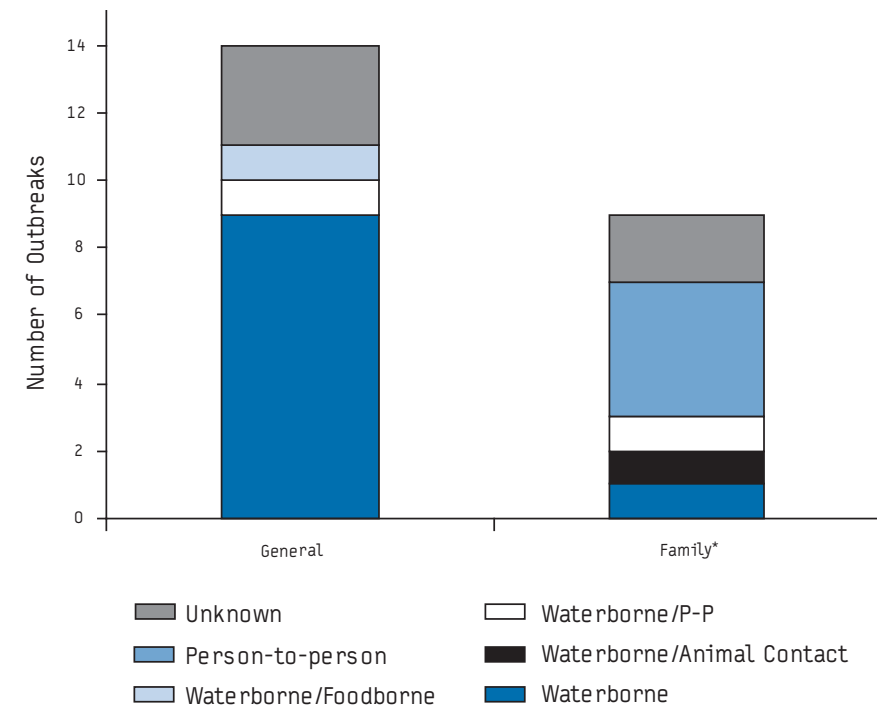

*Note: recreational water was suspected in two of the three family outbreaks where water was believed to have played a role in transmission outbreaks where water was believed to have played a role in transmiss Data source: Computerised Infectious Disease R
Protection Surveillance Centre (HPSC), Ireland increased the risk of $C$. parvum infection was touching or handling farm animals, while international travel, spending time sleeping or sitting on the ground and nappy-changing contact with a child less than five years of age were associated with $C$. hominis infection. No studies have been published in Ireland on the risk factors for sporadic cryptosporidiosis. Further research on this topic would be very valuable, in particular in the light of the seasonal distribution of cases and the likely difference in epidemiology that this suggests.

\section{Aknowledgements}

We wish to acknowledge the cooperation of hospital clinicians, general practitioners, microbiologists, medical scientists, senior medical officers, specialists in public health medicine, surveillance scientists and infection control nurses in providing the information upon which this report is based.

\section{References}

1. Glaberman S, Moore JE, Lowery CJ, Chalmers RM, Sulaiman I, Elwin K, et al. Three drinking-water-associated cryptosporidiosis outbreaks, Northern Ireland. Emerg Infect Dis 2002;8(6):631-3.

2. Mac Kenzie WR, Hoxie NJ, Proctor ME, Gradus MS, Blair KA, Peterson DE, et al A massive outbreak in Milwaukee of cryptosporidium infection transmitted through the public water supply. N Engl J Med. 1994;331(3):161-7.

3. Smith A, Reacher M, Smerdon W, Adak GK, Nichols G, Chalmers RM. Outbreaks of waterborne infectious intestinal disease in England and Wales, 1992-2003. Epidemiol Infect. 2006;134(6):1141-9.

4. Centers for Disease Control and Prevention (CDC). Cryptosporidiosis outbreaks associated with recreational water use--five states, 2006. MMWR Morb Mortal Wkly Rep. 2007;56(29):729-32.

5. Pelly H, Cormican M, O'Donovan D, Chalmers R, Hanahoe B, Cloughley R, Mckeown P, Corbett-Feeney G. A large outbreak of cryptosporidiosis in western Ireland linked to public water supply: a preliminary report. Euro Surveill. 2007;12(18):pii=3187. Available from: http://www.eurosurveillance. org/ViewArticle.aspx?ArticleId $=3187$

6. Health Protection Surveillance Centre (HPSC). Case definitions for notifiable diseases. 2003. Available from: http://www.ndsc.ie/hpsc/NotifiableDiseases/ CaseDefinitions/

7. Semenza JC, Nichols G. Cryptosporidiosis surveillance and water-borne outbreaks in Europe. Euro Surveill. 2007;12(5):pij=711. Available from: http:// www.eurosurveillance.org/ViewArticle.aspx?ArticleId=711

8. McLauchlin J, Amar C, Pedraza-Diaz S, Nichols GL. Molecular epidemiological analysis of Cryptosporidium spp. in the United Kingdom: results of genotyping Cryptosporidium spp. in 1,705 fecal samples from humans and 105 fecal samples from livestock animals. J Clin Microbiol. 2000;38(11):3984-90.

9. Strachan NJ, Ogden ID, Smith-Palmer A, Jones K. Foot and mouth epidemic reduces cases of human cryptosporidiosis in Scotland. J Infect Dis. 2003;188(5):783-6.

10. Lake IR, Nichols G, Bentham G, Harrison FC, Hunter PR, Kovats SR. Cryptosporidiosis decline after regulation, England and Wales, 1989-2005. Emerg Infect Dis. 2007;13(4):623-5.

11. Lake IR, Pearce J, Savill M. The seasonality of human cryptosporidiosis in New Zealand. Epidemiol Infect. 2008;136(10):1383-7.

12. Health Protection Surveillance Centre (HPSC). Report of the waterborne cryptosporidiosis subcommittee of the scientific advisory committee. 2004. Available from: http://www.ndsc.ie/hpsc/A-Z/Gastroenteric/Cryptosporidiosis/ Publications/WaterborneCryptosporidiosisSub-CommitteeReport/File,898,en. pdf

13. O'Toole CE, Jennings P, Meagher G, Kelly I. Cryptosporidium outbreak in continuously tested public water supply. Epi-Insight. 2004;5(10):1. Available from: http://www.hpsc.ie/hpsc/EPI-Insight/Volume52004/File,906,en.pdf

14. Nichols G, Chalmers R, Lake I, Sopwith W, Regan M, Hunter P, et al Cryptosporidiosis: A report on the surveillance and epidemiology of Cryptosporidium infection in England and Wales. Drinking Water Directorate Contract Number DWI 70/2/201. 2006. Available from: http://www.dwi.gov.uk/ research/reports/DWI70_2_201.pdf

15. Hunter PR, Hughes S, Woodhouse S, Syed Q, Verlander NQ, Chalmers RM, et al. Sporadic cryptosporidiosis case-control study with genotyping. Emerg Infect Dis. 2004;10(7):1241-9.

16. Hunter PR, Thompson RC. The zoonotic transmission of Giardia and Cryptosporidium. Int J Parasitol. 2005;35(11-12):1181-90. 
17. Leoni F, Amar C, Nichols G, Pedraza-Díaz S, McLauchlin J. Genetic analysis of Cryptosporidium from 2414 humans with diarrhoea in England between 1985 and 2000. J Med Microbiol. 2006;55(Pt 6):703-7

18. Hunter PR, Hadfield SJ, Wilkinson D, Lake IR, Harrison FC, Chalmers RM. Subtypes of Cryptosporidium parvum in humans and disease risk. Emerg Infect Dis. 2007;13(1):82-8.

19. Chalmers RM, Elwin K, Thomas AL, Guy EC, Mason B. Long-term Cryptosporidium typing reveals the aetiology and species-specific epidemiology of human cryptosporidiosis in England and Wales, 2000 to 2003. Euro Surveill. 2009;14(2):pij=19086. Available from: http://www.eurosurveillance.org/ ViewArticle.aspx?ArticleId=19086

20. Pedalino B, Garvey P, Igoe D. Cryptosporidiosis outbreak among Irish holidaymakers, Spain, July 2003. Epi-Insight. 2003:4(6):1. Available from: http://www.hpsc.ie/hpsc/EPI-Insight/Volume42003/File,673,en.PDF

21. Statutory Instrument. S.I. No. 707 of 2003. Infectious Diseases (Amendment) (No. 3) Regulations 2003. Irish Statute Book. Available from: http://www. irishstatutebook.ie/2003/en/si/0707.html

22. Zintl A, Proctor A, Read C, DeWaal T, Fanning S, Mulcahy G. What we know about the occurrence of Cryptosporidium in humans and domestic animals in Ireland. Workshop on Cryptosporidium in the Irish aquatic environment - sources, reservoirs and public health implications. Sligo: Institute of Technology; 2007. Available from: http://www.itsligo.ie/Workshops/cryptosporidium_workshop. html

23. Robertson B, Sinclair MI, Forbes AB, Veitch M, Kirk M, Cunliffe D, et al. Case control studies of sporadic cryptosporidiosis in Melbourne and Adelaide, Australia. Epidemiol Infect. 2002;128(3):419-31.

24. Roy SL, DeLong SM, Stenzel SA, Shiferaw B, Roberts JM, Khalakdina A, et al Emerging Infections Program FoodNet Working Group. Risk factors for sporadic cryptosporidiosis among immunocompetent persons in the United States from 1999 to 2001. J Clin Microbiol. 2004:42(7):2944-51.

25. Goh S, Reacher M, Casemore DP, Verlander NQ, Chalmers R, Knowles M, et al. Sporadic cryptosporidiosis, North Cumbria, England, 1996-2000. Emerg Infect Dis. 2004;10(6):1007-15.

26. Khalakdina A, Vugia DJ, Nadle J, Rothrock GA, Colford JM Jr. Is drinking water a risk factor for endemic cryptosporidiosis? A case-control study in the immunocompetent general population of the San Francisco Bay Area. BMC Public Health. 2003;3:11.

27. Lake IR, Harrison FC, Chalmers RM, Bentham G, Nichols G, Hunter PR, et al. Case-control study of environmental and social factors influencing cryptosporidiosis. Eur J Epidemiol. 2007;22(11):805-11.

This article was published on 26 February 2009.

Citation style for this article: Garvey P, Mckeown P. Epidemiology of human cryptosporidiosis in Ireland, 2004-2006: analysis of national notification data. Euro Surveill. 2009;14(8):pii=19128. Available online: http://www.eurosurveillance.org/ ViewArticle.aspx?ArticleId $=19128$ 